\title{
Divergent associations between incident hypertension and deprivation based on different sources of case identification
}

\author{
J. Aubé-Maurice, MD, MSc, FRCPC (1,2); L. Rochette, MSc (1); C. Blais, PhD (1,3)
}

This article has been peer reviewed.

\begin{abstract}
Introduction: Studies suggest that hypertension is more prevalent in the most deprived. Our objective was to examine the association between incident hypertension and deprivation in Quebec based on different modes of case identification, using two administrative databases.
\end{abstract}

Methods: We identified new incident cases of hypertension in 2006/2007 in the population aged 20 years plus. Socio-economic status was determined using a material and social deprivation index. Negative binomial regression analyses were carried out to examine the association between incident hypertension and deprivation, adjusting for several covariates.

Results: We found a positive and statistically significant association between material deprivation and incident hypertension in women, irrespective of the identifying database. Using the hospitalization database, the incidence of hypertension increased for both sexes as deprivation increased, except for social deprivation in women. However, whether using the physician billing database or the validated definition of hypertension obtained by combining data from the two databases, the incidence of hypertension decreased overall as deprivation increased.

Conclusions: Associations between hypertension and deprivation differ based on the database used: they are generally positively associated with the hospitalization database and inversely with the standard definition and the physician billing database, which suggests a consultation bias in favour of the most socio-economically advantaged.

Keywords: hypertension incidence, socio-economic status, administrative databases

\section{Introduction}

About 1 in 5 people have been diagnosed with arterial hypertension in Quebec, a proportion similar to that of the entire population of Canada. ${ }^{1,2}$ Moreover, the prevalence of hypertension increased by $29 \%$ in Quebec between 2000/2001 and $2006 / 2007$ and by $57 \%$ in Canada between 1998/1999 and 2007/2008. ${ }^{1,2}$ The incidence remained comparatively stable at the Canadian level, whereas it decreased slowly in Quebec, from approximately 31 per 1000 population in 2000/2001 to 25 per 1000 population in 2006/2007. ${ }^{1}$ The divergence between the change in prevalence and incidence over time is most likely due to a decline in mortality, probably as a result of better treatment and control. ${ }^{1,3}$ Because it is strongly associated with cardiovascular, renal and cerebrovascular diseases, suboptimal blood pressure is the risk factor associated with the greatest mortality in developed countries. ${ }^{4}$ Although an important cause of mortality and morbidity, ${ }^{5}$ hypertension is also a condition that can be modified. ${ }^{6-8}$ In fact, apart from age, sex, family antecedents and ethnic origin, most risk factors for hypertensionoverweight, physical inactivity, high salt and alcohol consumption and smoking ${ }^{9-11}$ are associated with lifestyle. It is also well accepted that some of these risk factors are unequally distributed, usually at the expense of those with lower socio-economic status (SES)., ${ }^{9,12}$

Several studies suggest at least a partial link between SES, particularly material deprivation, ${ }^{13}$ and hypertension. This link remains statistically significant even when adjusting for lifestyle characteristics ${ }^{9-11,14}$ and is often more pronounced in women. ${ }^{10}$ However, Tu et al. found no association between income alone and incident hypertension in Ontario. ${ }^{15}$ Research that examined the social component of deprivation ${ }^{13}$ found an association between social deprivation and hypertension. ${ }^{16-19}$ Most of the studies reviewed were cross-sectional and examined more specifically the relationship between prevalent hypertension and SES.

Our objective was to examine the association between incident hypertension and material and social deprivation in Quebec based on different modes of case identification, using two administrative databases. We expected to find a tendency similar to the one identified in the literature, namely, an inverse association between SES and incident hypertension that is more 
pronounced in women. We hypothesized that the most materially and socially advantaged people would present a lower incidence of hypertension, possibly as a result of a healthier lifestyle., ${ }^{9,20}$ We also supposed that this association would differ based on the administrative database used to identify the cases. In fact, we predicted that the hypertensive cases identified only on the hospitalization database present more comorbidities and a lower SES.

\section{Methods}

\section{Study population and data sources}

Our study population was aged 20 years and more, lived in Quebec between 2006-04-01 and 2007-03-31, and was identified as newly hypertensive based on a validated definition of hypertension ${ }^{21}$ that is used in Ontario ${ }^{15}$ and Quebec $^{1}$ and by the Public Health Agency of Canada.,22 The data used to identify hypertension cases were drawn from two administrative files, the physician billing and the hospitalization databases. The physician billing database compiles every medical procedure billed to the Régie de l'assurance maladie du Québec whereas the hospitalization database provides information about the principal diagnosis and up to 15 or 25 secondary diagnoses, depending on the year of compilation. ICD-10* codes have been used in the hospitalization database since 2006-04-01, whereas the ICD-9 ${ }^{+}$codes are still used in the physician billing database. The socio-demographic information from both databases is also found in the health insurance registry database. The data used are based on a longitudinal follow-up of hypertension since 1996-01-01. ${ }^{1}$

\section{Case definition}

The case definition of hypertension selected ("standard definition") corresponds to the following criteria: one hospitalization or two or more physician claims within two years, identified by one or more of the hypertension-related diagnoses codes: 401, 402, 403, 404 or 405 in ICD-9 or I10, I11, I12, I13 or I15 in ICD-10. This case definition has, according to a validation study conducted in Ontario, a sensitivity of $72 \%$, a specificity of $95 \%$, and a positive and negative predictive value of $87 \%$ and $88 \%$, respectively. ${ }^{21}$ According to this definition, the codes associated with hypertension identified within the 120 days preceding or 180 days following an obstetrical event (641-676 or V27 in ICD-9 or 01, O21-095, 098, 099 or Z37 in ICD-10) are excluded as they could be related to pregnancy-induced hypertension. In order to verify that the associations differed based on the source of case identification, the hypertensive individuals identified with the physician billing database were separated from those identified with the hospitalization database.

\section{Deprivation index}

As the administrative databases contain neither psychosocial nor material characteristics, we used the material and social deprivation index, a geographical proxy of the SES containing six indicators that can be linked to the administrative databases by postal code. ${ }^{13,23}$ These six indicators reflect the two types of deprivation, which were assigned to the individuals living within each census dissemination area. The material deprivation is determined by 1) the proportion of persons who have no high-school diploma; 2) the ratio of employment to population; and 3) average personal income. The social deprivation is determined by the proportion of 1) persons who are separated, divorced or widowed; 2) people living alone; and 3) single-parent families. With the exception of the last category, these indicators are adjusted for the age and sex. ${ }^{23}$ Each of the two components of the index is divided into quintiles, the most deprived people in the population being in the fifth quintile (Q5).

\section{Statistical analysis}

An exploratory descriptive analysis compared the profile of individuals in the general population with one identified as newly hypertensive. We used a negative binomial regression to examine the association between incident hypertension and material and social deprivation. Two models were used: the first included patients identified as newly hypertensive based on the standard definition, and the second distinguished the patients based on their identification database (hospitalization database versus physician billing database). The analysis was adjusted for age and geographical area of residence, and stratified for sex. The 2001 census was used as a reference for the adjustment of incidence rates for age. Analysis of material deprivation was adjusted for social deprivation, and vice versa. The reference group was the most advantaged (Q1). Interaction between age and sex and between deprivation and sex were verified. The statistical threshold for the analyses was $p \leq .05$. All the analyses were conducted using the statistical package SAS, version 9.1.3 (SAS Institute Inc.).

\section{Results}

The deprivation index could be assigned to $92 \%$ of our newly hypertensive cohort. Those who were unassigned did not have a permanent address or lived in areas where the index could not be attributed (as a result of being very small census geographical units, very sparsely populated or on Cree or Inuit territories and including health or social services institutions of more than 75 beds)..$^{13}$ Approximately $20 \%$ of the cases were identified with the hospitalization database and $80 \%$ with the physician billing database. Table 1 shows that $45 \%$ of the general population ( $\geq 20$ years) was aged between 20 and 44 years. In spite of being the largest in size, this age group had the smallest number of newly hypertensive cases, irrespective of the definition used.

Table 2 shows approximately $20 \%$ of the population in each deprivation quintile, as expected. The subsequent exclusion from each quintile of people aged less than 20 years and those for whom no deprivation index could be assigned explains why each does not represent exactly $20 \%$ of the population. Using the standard definition, and after excluding the most advantaged quintile (Q1), the incidence of hypertension decreased as the level of material deprivation increased. The association was the same for social deprivation, but the increase was

\footnotetext{
* International Classification of Diseases, 10th Revision.

+ International Classification of Diseases, 9th Revision.
} 
TABLE 1

Distribution of the study population according to method of case identification and age-specific incidence rate, 2006/2007, Quebec, Canada

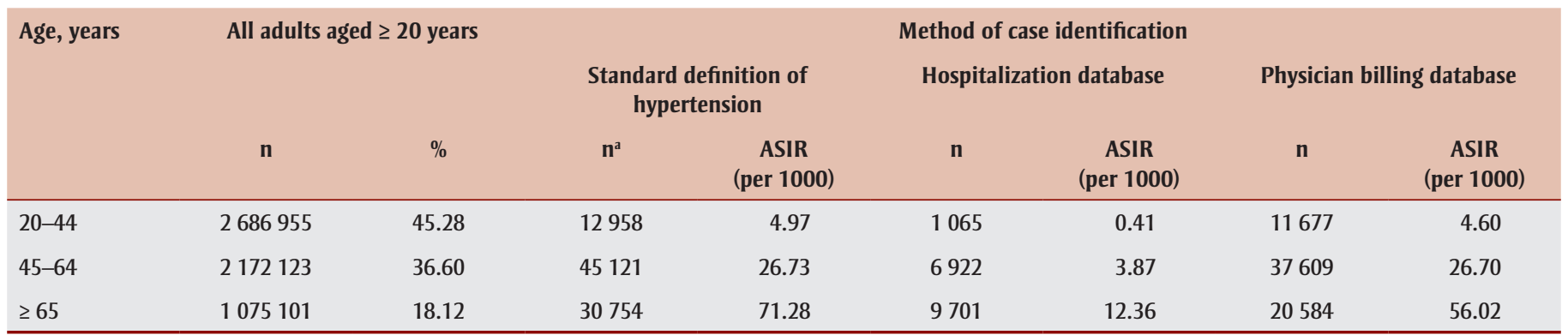

Abbreviation: ASIR, age-specific incidence rate.

Note: The study population consists of adults aged $\geq 20$ years and newly identified as hypertensive.

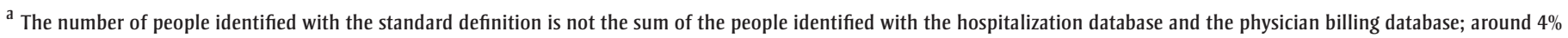
of the people are identified with both databases. These $4 \%$ are only included in the standard definition.

TABLE 2

Characteristics of study population according to the method of case identification and age-adjusted incidence rate, 2006/2007, Quebec, Canada

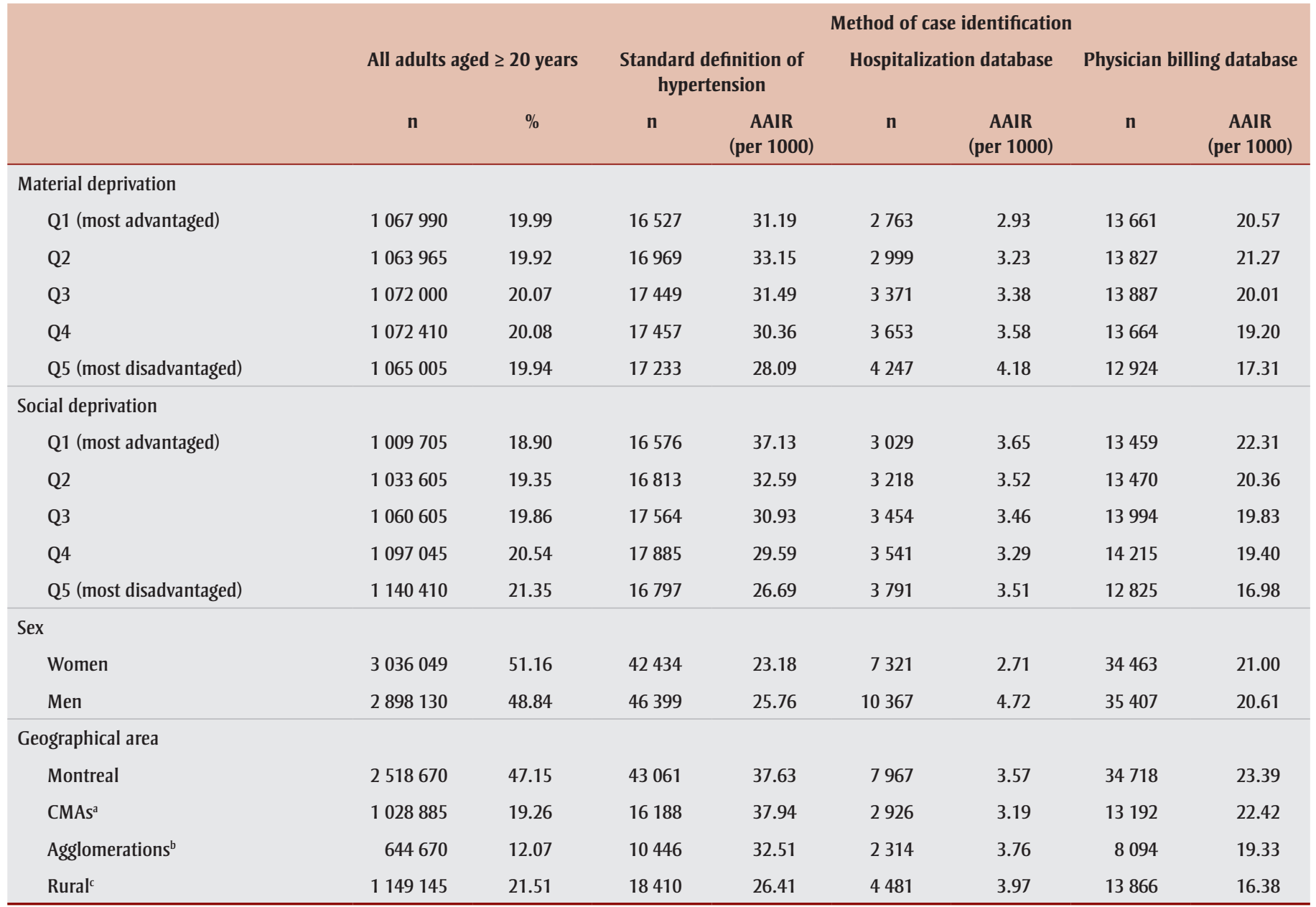

Abbreviations: AAIR, average age-adjusted incidence rate; CMA, census metropolitan area; Q, quintile.

Notes: Q1 = most advantaged; Q5 = most disadvantaged

The study population consists of adults aged $\geq 20$ years and newly identified as hypertensive.

a Other census metropolitan areas, populations > 100000 inhabitants (Québec, Sherbrooke, Trois-Rivières, Saguenay and Gatineau).

${ }^{\mathrm{b}}$ Mid-size cities, population $10000-100000$ inhabitants.

c Small towns and rural settings, populations $<10000$. 
larger and steadier. The associations differ when we take into account the database used for case identification: using the hospitalization database, hypertension increases as material deprivation increases, whereas the association is less pronounced for social deprivation; for cases identified with the physician billing database, hypertension decreases as the level of material and social deprivation increases, the same as with the standard definition. Men identified with the hospitalization database show an incidence of hypertension almost twice that of women (4.72 per 1000 population versus 2.71 per 1000 population) (see Table 2). The incidence rate of hypertension is higher in urban areas with the standard definition and with the physician billing database than with the hospitalization database.

Table 3 shows the results of the multivariate analyses. We did not find any statistically significant interactions between each type of deprivation and method of case identification, that is, physician billing database or hospitalization database. As the interaction between age and sex was statistically significant ( $p=.0011$ ), the results are stratified by sex. The results obtained with the standard definition showed a positive association between age and incident hypertension for both sexes, with the oldest age group ( $\geq 65$ years) having a relative risk of hypertension 7 times that of the youngest age group (20-44 years). Figure 1 shows the same positive associations between age and hypertension with the hospitalization and physician databases. Women and men in the oldest age group ( $\geq 65$ years) have an adjusted incidence rate of hypertension 24 and 29 times, respectively, that of those in the youngest group (20-44 years) when identified with the hospitalization database. The positive association between age and hypertension is less pronounced when using the physician billing database (relative risk $[R R] \approx 5$ times).

As in Table 3, Figure 2 shows a positive and statistically significant association between material deprivation in women and incidence of hypertension, as defined by the standard definition $\left(\mathrm{RR}_{\mathrm{Q} 5}=1.15\right)$. The association between social deprivation and incident hypertension in women is the opposite $\left(\mathrm{RR}_{\mathrm{Q} 5}=0.83\right)$ to that of material deprivation, and is statistically significant only for Q4 and Q5. There was no significant association between material deprivation and the incidence of hypertension in men, but social deprivation influences the incidence of hypertension for men in the same way as for women $\left(\mathrm{RR}_{\mathrm{Q} 5}=0.87\right)$, the association also being statistically significant only for Q4 and Q5.

For cases identified with the hospitalization database (Table 3 and Figure 3), there is a positive and statistically significant association between material deprivation and the incidence of hypertension in women $\left(\mathrm{RR}_{\mathrm{Q} 5}=1.60\right)$, though the association between incident hypertension and social deprivation is not statistically significant. In men, the association between the incidence of hypertension and material deprivation is also positive, but it is statistically significant only for $\mathrm{Q} 3$ to $\left.\mathrm{Q} 5 \mathrm{RR}_{\mathrm{O} 5}=1.29\right)$. The association between incident hypertension and social deprivation in this group is positive but statistically significant only for the most deprived quintile $\left(\mathrm{RR}_{\mathrm{Q} 5}=1.14\right)$.

When incident cases are identified with the physician billing database (Table 3 and Figure 4), the associations are similar to those found using the standard definition. In women, the positive association between material deprivation and hypertension is weak and statistically significant only for Q3 to Q5 $\left(\mathrm{RR}_{\mathrm{Q} 5}=1.07\right)$. In contrast, there is an inverse association between hypertension and social deprivation that is statistically significant only for Q4 and $\mathrm{Q} 5\left(\mathrm{RR}_{\mathrm{Q} 5}=0.80\right)$. In men, the association between material deprivation and the incidence of hypertension is inversely related but statistically significant only for the most deprived quintile, $\mathrm{Q} 5\left(\mathrm{RR}_{\mathrm{Q} 5}=0.94\right)$, while the level of social deprivation is, as for women, inversely associated with incident hypertension and statistically significant only for $\mathrm{Q} 3$ to $\mathrm{Q} 5\left(\mathrm{RR}_{\mathrm{Q} 5}=0.81\right)$.

\section{Discussion}

Our results demonstrate divergent associations between the incidence of hypertension and deprivation in people aged 20 years and more in Quebec during

FIGURE 1

Adjusted relative risk of men and women by the standard definition of hypertension and methods of case identification, by age, 2006/2007, Quebec, Canada

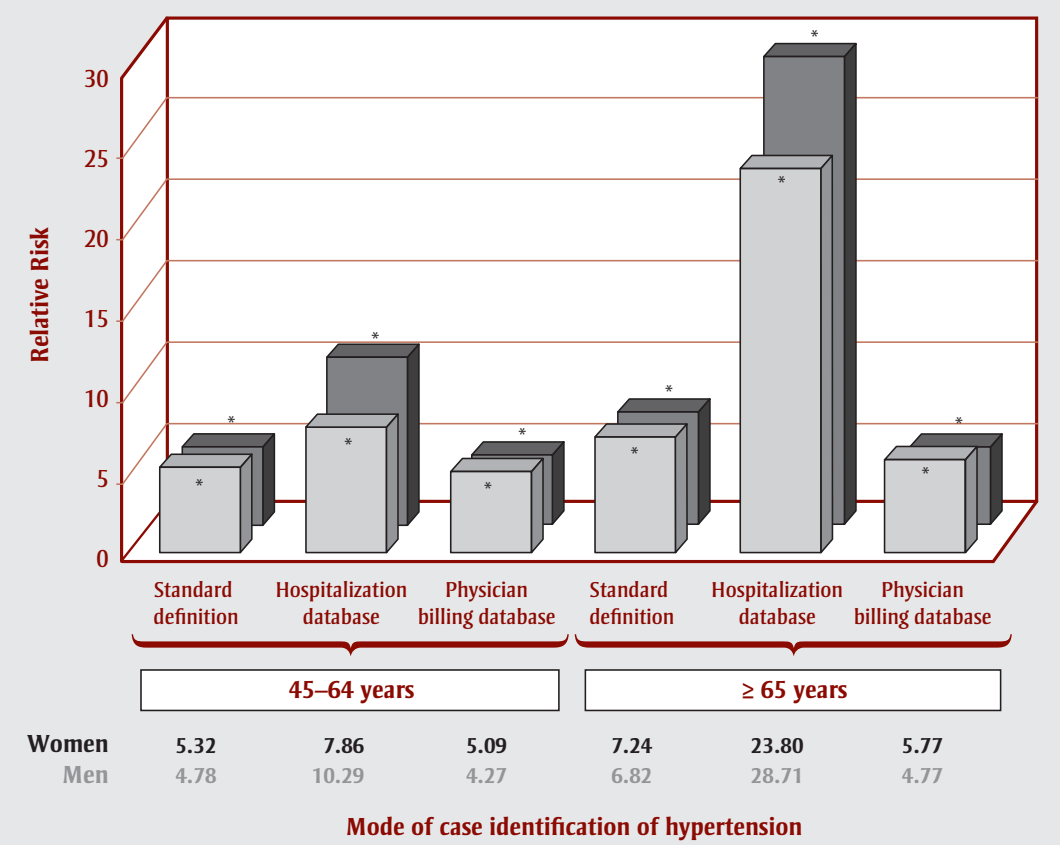

Notes: The relative risks for the people aged between $20-44$ years were chosen as the reference and are not shown in this graph. The relative risks for the $45-64$ and $\geq 65$ years age groups were adjusted for the level of material and social deprivation and the area of residence.

The study population consists of adults aged $\geq 20$ years and newly identified as hypertensive.

* Statistically significant results, $p<.0001$. 
TABLE 3

Relative risk of male and female study population according to the method of case identification, by age, geographical area of residence, and material and social deprivation, 2006/2007, Quebec, Canada

\begin{tabular}{|c|c|c|c|c|c|c|c|c|c|}
\hline & \multicolumn{9}{|c|}{ Method of case identification } \\
\hline & \multicolumn{3}{|c|}{ Standard definition of hypertension } & \multicolumn{3}{|c|}{ Hospitalization database } & \multicolumn{3}{|c|}{ Physician billing database } \\
\hline & $\mathbf{R R}$ & $95 \% \mathrm{Cl}$ & $p$ & $\mathbf{R R}$ & $95 \% \mathrm{Cl}$ & $p$ & $\mathbf{R R}$ & $95 \% \mathrm{Cl}$ & $\boldsymbol{p}$ \\
\hline \multicolumn{10}{|l|}{ Women } \\
\hline \multicolumn{10}{|l|}{ Age, years } \\
\hline $20-44$ (ref) & 1.00 & - & - & 1.00 & - & - & 1.00 & - & - \\
\hline $45-64$ & $5.32^{*}$ & $5.10-5.55$ & $<.0001$ & $7.86^{*}$ & $7.02-8.82$ & $<.0001$ & $5.09^{*}$ & $4.87-5.33$ & $<.0001$ \\
\hline$\geq 65$ & $7.24^{*}$ & $6.93-7.56$ & $<.0001$ & $23.80^{*}$ & $21.30-26.64$ & $<.0001$ & $5.77^{*}$ & $5.51-6.04$ & $<.0001$ \\
\hline \multicolumn{10}{|l|}{ Geographical area } \\
\hline Montreal (ref) & 1.00 & - & - & 1.00 & - & - & 1.00 & - & - \\
\hline $\mathrm{CMAs}^{\mathrm{a}}$ & $0.89^{*}$ & $0.85-0.93$ & $<.0001$ & $0.86^{*}$ & $0.79-0.94$ & .0011 & $0.90^{*}$ & $0.86-0.94$ & $<.0001$ \\
\hline Agglomerations $^{b}$ & $0.89^{*}$ & $0.85-0.93$ & $<.0001$ & 1.05 & $0.95-1.16$ & .3127 & $0.86^{*}$ & $0.82-0.90$ & $<.0001$ \\
\hline Rural $^{\mathrm{C}}$ & $0.82^{*}$ & $0.78-0.85$ & $<.0001$ & 1.04 & $0.95-1.14$ & .4389 & $0.78^{*}$ & $0.74-0.82$ & $<.0001$ \\
\hline \multicolumn{10}{|l|}{ Material deprivation } \\
\hline Q1 (most advantaged) (ref) & 1.00 & - & - & 1.00 & - & - & 1.00 & - & - \\
\hline Q2 & $1.06^{*}$ & $1.00-1.12$ & .0321 & $1.13^{*}$ & $1.01-1.26$ & .0375 & 1.05 & $0.99-1.11$ & .0712 \\
\hline Q3 & $1.07^{*}$ & $1.02-1.13$ & .0091 & $1.18^{*}$ & $1.05-1.32$ & .0040 & $1.06^{*}$ & $1.00-1.12$ & .0364 \\
\hline Q4 & $1.10^{*}$ & $1.04-1.16$ & .0004 & $1.32^{*}$ & $1.18-1.48$ & $<.0001$ & $1.06^{*}$ & $1.01-1.13$ & .0292 \\
\hline Q5 (most disadvantaged) & $1.15^{*}$ & $1.09-1.21$ & $<.0001$ & $1.60^{*}$ & $1.43-1.79$ & $<.0001$ & $1.07^{*}$ & $1.01-1.14$ & .0153 \\
\hline \multicolumn{10}{|l|}{ Social Deprivation } \\
\hline Q1 (most advantaged) (ref) & 1.00 & - & - & 1.00 & - & - & 1.00 & - & - \\
\hline Q2 & 0.97 & $0.92-1.02$ & .2367 & 1.01 & $0.90-1.12$ & .9182 & 0.97 & $0.91-1.02$ & .2152 \\
\hline Q3 & 0.95 & $0.91-1.00$ & .0589 & 0.99 & $0.89-1.10$ & .8381 & 0.95 & $0.90-1.00$ & .0671 \\
\hline Q4 & $0.92^{*}$ & $0.88-0.97$ & .0012 & 0.95 & $0.85-1.06$ & .3653 & $0.92^{*}$ & $0.87-0.97$ & .0023 \\
\hline Q5 (most disadvantaged) & $0.83^{*}$ & $0.79-0.88$ & $<.0001$ & 1.04 & $0.93-1.16$ & .4553 & $0.80^{*}$ & $0.76-0.85$ & $<.0001$ \\
\hline \multicolumn{10}{|l|}{ Men } \\
\hline \multicolumn{10}{|l|}{ Age, years } \\
\hline $20-44$ (ref) & 1.00 & - & - & 1.00 & - & - & 1.00 & - & - \\
\hline $45-64$ & $4.78^{*}$ & $4.62-4.96$ & $<.0001$ & $10.29^{*}$ & $9.39-11.28$ & $<.0001$ & $4.27^{*}$ & $4.12-4.43$ & $<.0001$ \\
\hline$\geq 65$ & $6.82^{*}$ & $6.57-7.08$ & $<.0001$ & $28.71^{*}$ & $26.24-31.45$ & $<.0001$ & $4.77^{*}$ & $4.59-4.96$ & $<.0001$ \\
\hline \multicolumn{10}{|l|}{ Geographical area } \\
\hline Montreal (ref) & 1.00 & - & - & 1.00 & - & - & 1.00 & - & - \\
\hline $\mathrm{CMAs}^{\mathrm{a}}$ & $0.90^{*}$ & $0.87-0.93$ & $<.0001$ & $0.91^{*}$ & $0.85-0.98$ & .0089 & $0.90^{*}$ & $0.86-0.93$ & $<.0001$ \\
\hline Agglomerations ${ }^{b}$ & $0.89^{*}$ & $0.86-0.93$ & $<.0001$ & 1.05 & $0.98-1.13$ & .1859 & $0.84^{*}$ & $0.81-0.88$ & $<.0001$ \\
\hline Rural $^{c}$ & $0.87^{*}$ & $0.84-0.90$ & $<.0001$ & 1.06 & $0.99-1.14$ & .0737 & $0.81^{*}$ & $0.78-0.85$ & $<.0001$ \\
\hline \multicolumn{10}{|l|}{ Material deprivation } \\
\hline Q1 (most advantaged) (ref) & 1.00 & - & - & 1.00 & - & - & 1.00 & - & - \\
\hline Q2 & 1.01 & $0.96-1.05$ & .8265 & 1.08 & $1.00-1.18$ & .0579 & 0.99 & $0.95-1.04$ & .8244 \\
\hline Q3 & 1.01 & $0.96-1.06$ & .6954 & $1.15^{*}$ & $1.06-1.25$ & .0010 & 0.99 & $0.94-1.03$ & .5721 \\
\hline Q4 & 1.00 & $0.96-1.05$ & .8563 & $1.18^{*}$ & $1.09-1.29$ & $<.0001$ & 0.97 & $0.93-1.02$ & .2441 \\
\hline Q5 (most disadvantaged) & 1.00 & $0.96-1.05$ & .8354 & $1.29^{*}$ & $1.18-1.40$ & $<.0001$ & $0.94^{*}$ & $0.90-0.99$ & .0213 \\
\hline \multicolumn{10}{|l|}{ Social Deprivation } \\
\hline Q1 (most advantaged) (ref) & 1.00 & - & - & 1.00 & - & - & 1.00 & - & - \\
\hline Q2 & 0.98 & $0.94-1.02$ & .2931 & 1.02 & $0.94-1.10$ & .6976 & 0.97 & $0.93-1.01$ & .1850 \\
\hline Q3 & 0.97 & $0.93-1.01$ & .1351 & 1.05 & $0.97-1.14$ & .2184 & $0.95^{*}$ & $0.91-1.00$ & .0322 \\
\hline Q4 & $0.93^{*}$ & $0.89-0.97$ & .0011 & 1.05 & $0.97-1.13$ & .2579 & $0.91^{*}$ & $0.86-0.95$ & $<.0001$ \\
\hline Q5 (most disadvantaged) & $0.87^{*}$ & $0.83-0.91$ & $<.0001$ & $1.14^{*}$ & $1.05-1.24$ & .0015 & $0.81^{*}$ & $0.77-0.85$ & $<.0001$ \\
\hline
\end{tabular}

Abbreviations: $\mathrm{Cl}$, confidence interval; ref, reference; $\mathrm{RR}$, relative risk; $\mathrm{Q}$, quintile.

Note: Q1 = most advantaged; Q5 = most disadvantaged.

The study population consists of adults aged $\geq 20$ years and newly identified as hypertensive.

${ }^{\mathrm{a}}$ Other census metropolitan areas, populations > 100000 inhabitants (Québec, Sherbrooke, Trois-Rivières, Saguenay and Gatineau).

${ }^{\mathrm{b}}$ Mid-size cities, population 10 000-100 000 inhabitants.

c Small towns and rural settings, populations $<10000$.

* Statistically significant results, $p \leq .05$. 
FIGURE 2

Adjusted relative risk of men and women by the standard definition of hypertension and material and social deprivation, 2006/2007, Quebec, Canada

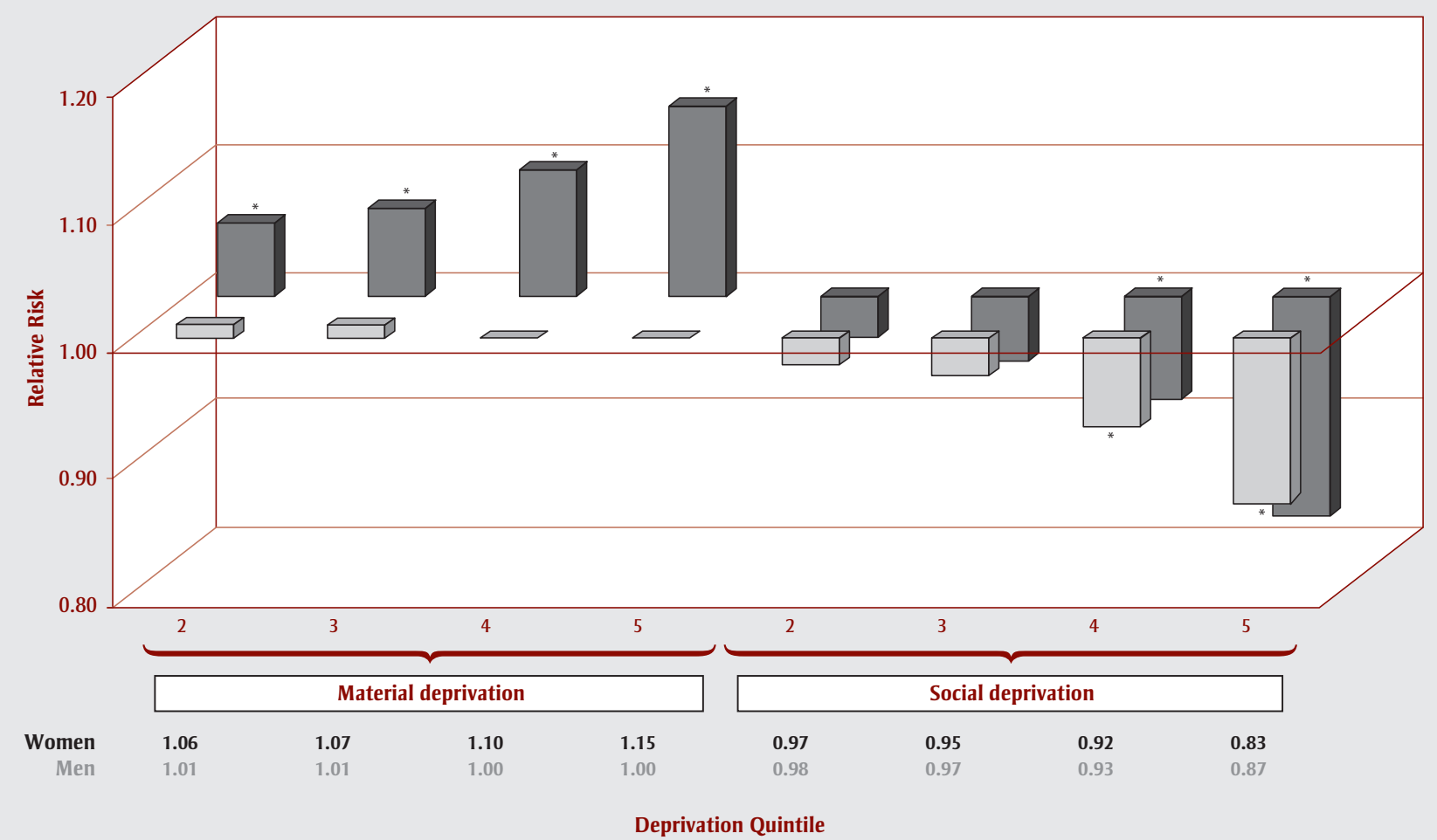

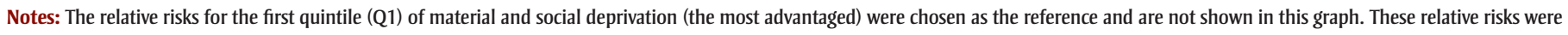
also adjusted for age and the geographical area of residence.

The study population consists of adults aged $\geq 20$ years and newly identified as hypertensive.

* Statistically significant results, $p \leq .05$.

the fiscal year 2006/2007. These associations vary based on the source of case identification, the type of deprivation, and sex. Associations between the incidence of hypertension and deprivation are generally positive when individuals were identified with the hospitalization database as opposed to the physician billing database or the standard definition. Associations made with the hospitalization database are also more pronounced and more constant than those made with the physician billing database.

Several of the associations observed in our study differ from those found in the literature. ${ }^{10,11,16,17}$ To explain the unexpected results for cases identified with the physician billing database or with the standard definition, it is important to emphasize that the definition of hypertension we chose involves medical consultations, whereas most other studies reviewed relied mainly on surveys. Our results suggest that the most advantaged people visit a doctor in a medical practice more frequently, increasing the likelihood of identifying hypertension, which results in a consultation bias with more frequent identification of hypertension. However, the research varies on this issue. ${ }^{20,24}$ Our results show that material deprivation is associated with a decrease in the incidence of hypertension in men identified with the physician billing database. Pineault et al. found that individuals identified with cardiovascular risk factors, including hypertension, were more likely to be older, male and less educated. ${ }^{24}$ However, even if the risk factor group had difficulty accessing primary care services, access was not statistically different compared to other users. ${ }^{24}$

On the other hand, some studies showed that individuals with a lower SES use ambulatory medical services more frequently. ${ }^{25,26}$ However, these ambulatory visits reflect both emergency room and medical office visits, two very different types of physician consultations. Although both are included in the physician billing database, the people who rely on the emergency room visits are probably less likely to benefit from the long-term care required for certain medical conditions including hypertension and thus more likely to experience subsequent hospitalizations due to the deterioration of the medical condition; follow-up medical visits are indeed known to reduce hospitalization. ${ }^{27}$ Moreover, an asymptomatic health condition such as hypertension is less likely to be identified as a diagnosis in the physician billing database by emergency doctors compared to family physicians who see a patient as part of a medical follow-up. It is also possible, especially in the emergency room, that the diagnosis of more urgent medical conditions supersedes the hypertension diagnoses for more deprived people who often present with several conditions, ${ }^{28}$ which would lead 
to the frequency of hypertension being underestimated in this group. Interestingly, some studies have suggested that the most socioeconomically deprived individuals are more likely to seek medical care in an emergency context, ${ }^{29,30}$ and some authors have shown that these ambulatory consultations were less likely to prevent hospitalization in the most deprived people of the society. ${ }^{31}$ Two Canadian studies showed that lower income is positively associated with emergency department visits $^{32}$ and inversely associated with continuity of care, ${ }^{33}$ which is defined as a "long-term relationship between a patient and a physician or a patient and a physician group, regardless of the presence of any specific disease." ${ }^{33}$ However, another Canadian study demonstrated the opposite. ${ }^{34}$

In contrast, the association between material deprivation and hypertension in women shows the same tendency as described in the literature, regardless of the source of case identification. The data suggests that the use of medical services by women is less influenced by material deprivation. In fact, Birch et al. found that women were more likely to have consulted a family physician in the previous year compared with men. ${ }^{35}$ Broyles et al. suggested that this was a result of women, especially those of childbearing age, being more heavily involved in maternity and family planning. ${ }^{36}$ Medical consultations for cervical cancer screening, renewal of oral contraceptives and, at around age fifty years, breast cancer screening could also be contributing to this phenomenon. Several studies also showed that women were more concerned about and aware of hypertension than men. ${ }^{37-41}$

In addition, Birch et al. found a positive association between the frequency of contacts with friends or relatives and the number of visits to a doctor. ${ }^{35}$ Thus, compared to the most socially deprived, the most socially advantaged would be more likely to be diagnosed with a condition such as hypertension. This goes towards explaining the reverse association between social deprivation and hypertension identified with both the physician billing database and the standard definition for both sexes.

According to Billings et al., compared to those living in more advantaged areas, people living in deprived areas tend to delay consulting a physician for the treatment of manageable conditions, which leads to more frequent avoidable hospitalization. ${ }^{42}$ This delay may be associated with decreased access to health care services for disadvantaged people, even in a country like Canada with a public health care system. Other studies showed that the most deprived individuals use hospital services more often. ${ }^{43-45}$ Since hypertension is a frequent asymptomatic comorbidity, ${ }^{1,15}$ it is likely to be omitted from the list of secondary diagnoses collected in the hospital record of patients with several comorbidities. Thus, since the most materially deprived people have more comorbidities, ${ }^{46}$ our results may

FIGURE 3

Adjusted relative risk of men and women as identified by the hospitalization database, by material and social deprivation, 2006/2007, Quebec, Canada

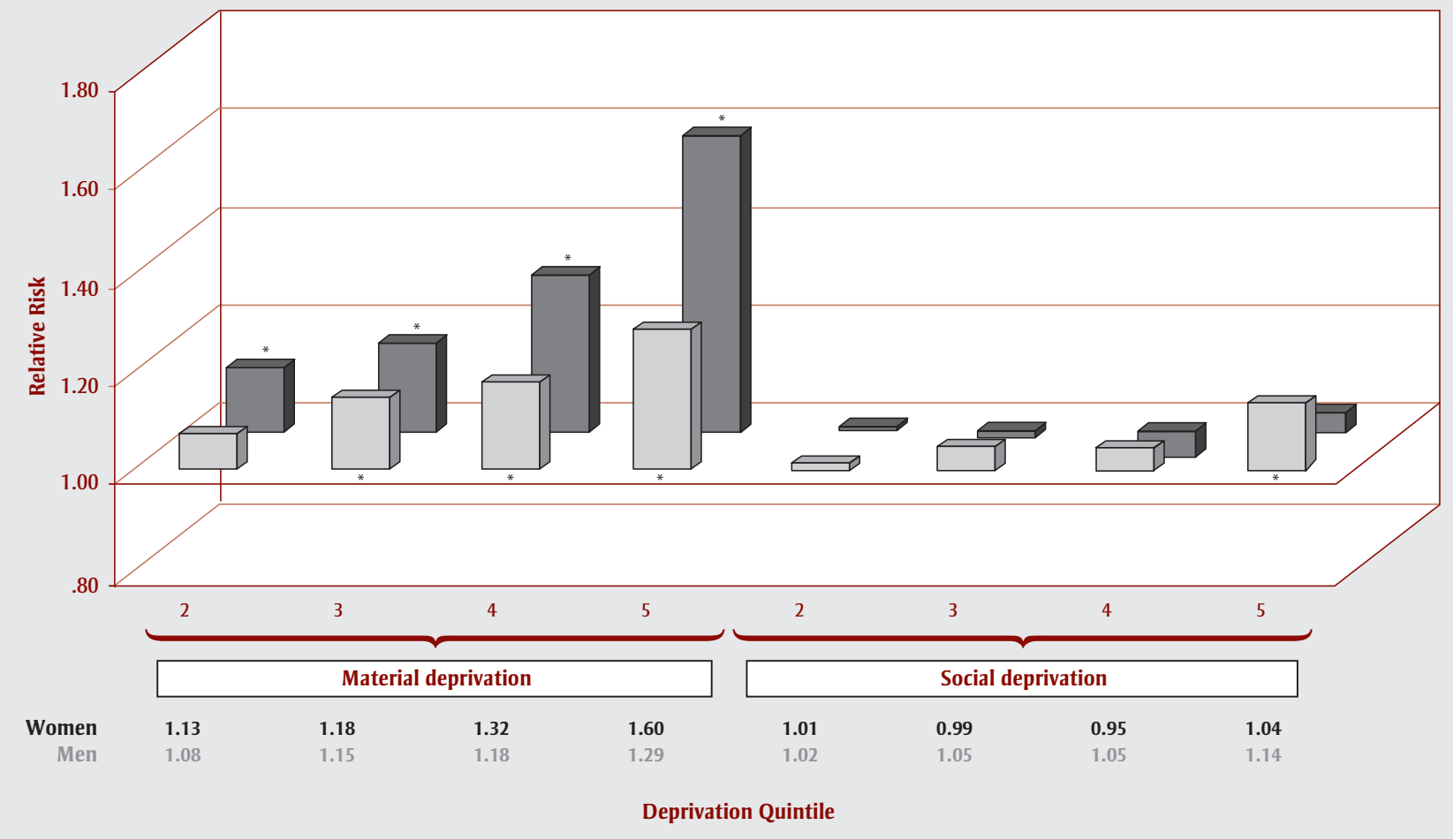

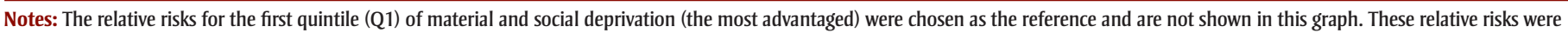
also adjusted for the geographical area of residence and age.

The study population consists of adults aged $\geq 20$ years and newly identified as hypertensive.

* Statistically significant results, $p \leq .05$. 
FIGURE 4

Adjusted relative risk of men and women as identified by the physician billing database, by material and social deprivation, 2006/2007, Quebec, Canada

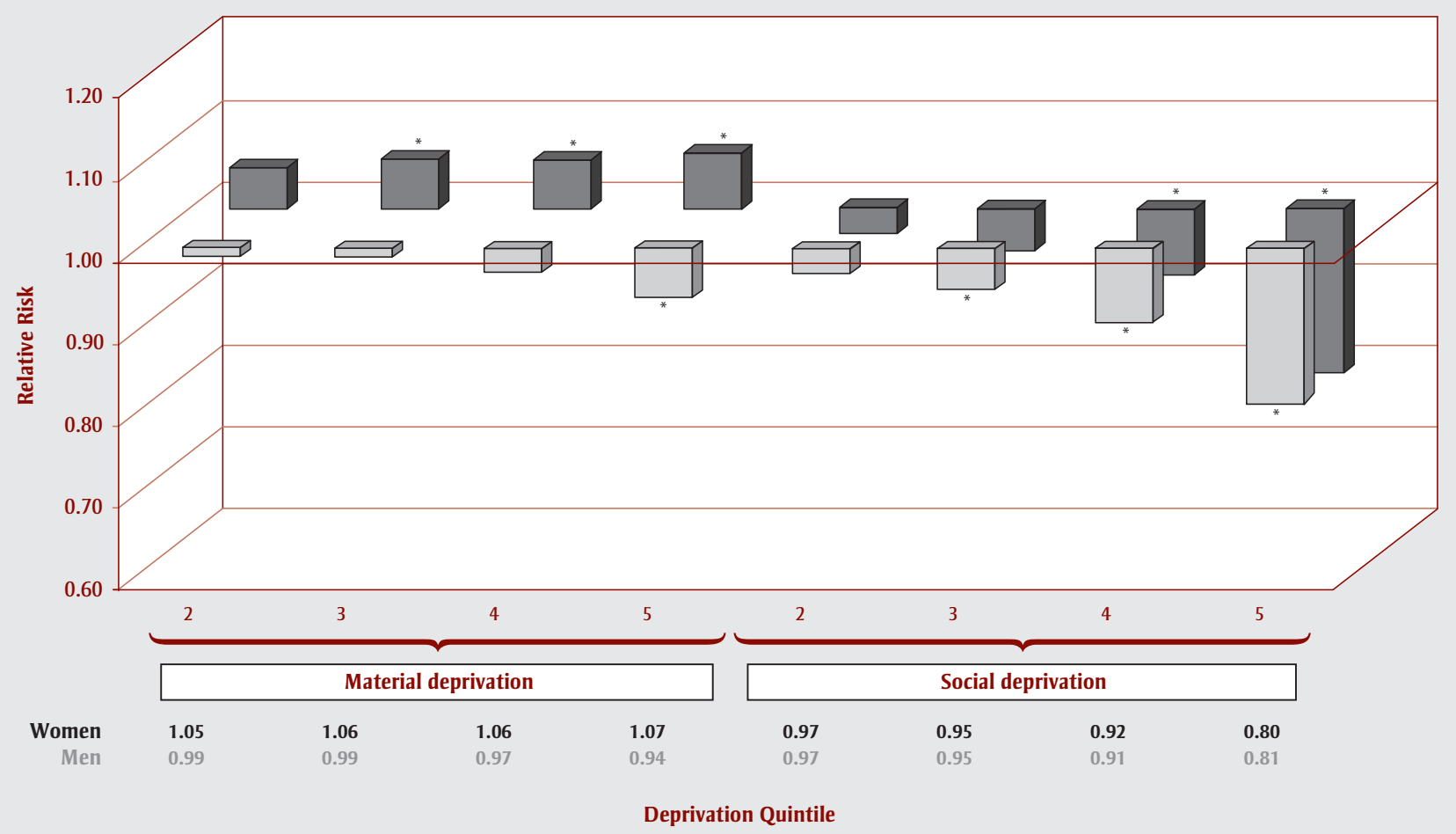

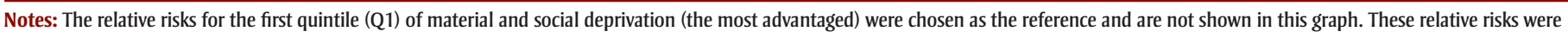
also adjusted for the geographical area of residence and age.

The study population consists of adults aged $\geq 20$ years and newly identified as hypertensive.

* Statistically significant results, $p \leq .05$.

underestimate the positive association found between deprivation and hypertension identified with the hospitalization database.

\section{Limitations}

Some limitations are associated with the use of administrative databases, not least that these exclude people with hypertension who have not consulted any health care professionals. The asymptomatic presentation of hypertension probably increases the risk of such a bias, with the detection of hypertension probably varying with SES. Moreover, in their validation study, Tu et al. concluded that the standard definition fails to identify up to $28 \%$ of hypertensive patients compared to the consultation of primary care physician charts. ${ }^{21}$ However, there is no reason to believe that individuals identified as hypertensive with the primary care physician charts alone are different from those identified with our case definition. The physician billing administrative database is used primarily to compile acts rather than diagnosis, and may therefore miss certain diagnoses such as hypertension; this may partly explain this proportion of unidentified hypertensive patients. However, in our study population, these omissions represent less than $10 \%$ of the physician billing acts. It is also important to underline that the deprivation index is not an individual measure of socio-economic conditions, but rather a measure of the conditions at the neighbourhood level. Finally, our data sources relied on two different editions of ICD codes. However, since there was no new ICD code for hypertension between the ninth and the tenth revisions, this difference is not likely to affect our results.

\section{Conclusion}

This study reaffirms the importance of considering social and material health inequalities when planning interventions targeted at preventing hypertension. It suggests different health service utilisation based on SES, and thus inequalities in medical detection, treatment and control of hypertension at the expense of the most deprived. In the light of our results, it would be interesting to refine our understanding of primary health care access based on deprivation, to better understand how it varies in different health care settings such as family physicians' practices, walk-in clinics, and emergency care, of which the first is in a much better position to follow up on chronic health conditions. It would also be of value to policy makers to improve our understanding of the potential barriers to health care services and the strategies that can be used to address these, given that universal health care has been in operation in Canada for decades.

\section{Acknowledgements}

The authors gratefully acknowledge the following from the Institut national de santé publique du Québec: Denis Hamel for the study design, Robert Pampalon for interpreting the results, 
Najwa Ouhoummane for suggesting new analyses and interpreting the results, Philippe Gamache for his statistical contributions, Jean-Frédéric Lévesque for the transmission of new results and Danielle Saint-Laurent for her advice. We also thank the Public Health Agency of Canada for their help in funding this project and Chris Waters from the Public Health Agency of Canada for the SAS code.

\section{References}

1. Blais C, Rochette L. Surveillance de l'hypertension au Québec: incidence, prévalence et mortalité. Québec (QC): Institut national de santé publique du Québec; 2011. Available at: http:// www.inspq.qc.ca/pdf/publications /1059_HypertensionArterielle.pdf

2. Robitaille C, Dai S, Waters C, Loukine L, Bancej C, Quach S, et al. Diagnosed hypertension in Canada: incidence, prevalence and associated mortality. CMAJ. 2012;184(1):E49-56 [online version consulted 2011 Nov 21].

3. Tu K, Chen Z, Lipscombe LL; Canadian Hypertension Education Program Outcomes Research Taskforce. Mortality among patients with hypertension from 1995 to 2005: a population-based study. CMAJ. 2008;178(11):1436-40.

4. Ezzati M, Lopez AD, Rodgers A, Vander Hoorn S, Murray CJ. Comparative Risk Assessment Collaborating Group. Selected major risk factors and global and regional burden of disease. Lancet. 2002;360(9343):1347-60.

5. Organisation mondiale de la santé. Rapport sur la santé dans le monde 2002: Réduire les risques et promouvoir une vie saine. Geneva (CH): WHO; 2002.

6. Goldstein LB, Adams R, Alberts MJ, Appel LJ, Brass LM, Bushnell CD, et al. Primary prevention of ischemic stroke: a guideline from the American Heart Association/American Stroke Association Stroke Council: cosponsored by the Atherosclerotic Peripheral Vascular Disease Interdisciplinary Working Group; Cardiovascular Nursing Council; Clinical Cardiology Council; Nutrition, Physical Activity, and Metabolism Council; and the Quality of Care and Outcomes Research
Interdisciplinary Working Group: the American Academy of Neurology affirms the value of this guideline. Stroke. 2006;37(6):1583-633.

7. Lee DE, Cooper RS. Recommendations for global hypertension monitoring and prevention. Curr Hypertens Rep. 2009;11(6):444-9.

8. Santé Canada, Coalition canadienne pour la prévention et le traitement de l'hypertension. Stratégie nationale de prévention et de traitement de l'hypertension: rapport sommaire du Groupe d'experts. Ottawa (ON): Health Canada; 2000. p. 1-27.

9. Bell AC, Adair LS, Popkin BM. Understanding the role of mediating risk factors and proxy effects in the association between socio-economic status and untreated hypertension. Soc Sci Med. 2004;59(2):275-83.

10. Colhoun HM, Hemingway H, Poulter NR. Socio-economic status and blood pressure: an overview analysis. J Hum Hypertens. 1998;12(2):91-110.

11. Levenstein S, Smith MW, Kaplan GA. Psychosocial predictors of hypertension in men and women. Arch Intern Med. 2001;161(10):1341-6.

12. Public Health Agency of Canada, Canadian Institute for Health Information, Canadian Stroke Network, Heart and Stroke Foundation of Canada, Statistics Canada, editors. Suivi des maladies du cœur et des accidents vasculaires cérébraux au Canada. Ottawa (ON): Public Health Agency of Canada; 2009. p. 1-118. [Catalogue No.: HP32-3/2009F].

13. Pampalon R, Raymond G. A deprivation index for health and welfare planning in Quebec. Chronic Dis Can. 2000;21(3):104-13.

14. Matheson FI, White HL, Moineddin R, Dunn JR, Glazier RH. Neighbourhood chronic stress and gender inequalities in hypertension among Canadian adults: a multilevel analysis. J Epidemiol Community Health. 2010;64(8):705-13.
15. Tu K, Chen Z, Lipscombe LL. Canadian Hypertension Education Program Outcomes Research Taskforce. Prevalence and incidence of hypertension from 1995 to 2005: a population-based study. CMAJ. 2008;178(11):1429-35.

16. Uchino BN, Cacioppo JT, Kiecolt-Glaser JK. The relationship between social support and physiological processes: a review with emphasis on underlying mechanisms and implications for health. Psychol Bull. 1996;119(3):488-531.

17. Tomaka J, Thompson S, Palacios R. The relation of social isolation, loneliness, and social support to disease outcomes among the elderly. J Aging Health. 2006;18(3):359-84.

18. Hawkley LC, Masi CM, Berry JD, Cacioppo JT. Loneliness is a unique predictor of age-related differences in systolic blood pressure. Psychol Aging. 2006;21(1):152-64.

19. Thorpe RJ Jr, Brandon DT, LaVeist TA. Social context as an explanation for race disparities in hypertension: findings from the Exploring Health Disparities in Integrated Communities (EHDIC) Study. Soc Sci Med. 2008;67(10):1604-11.

20. Daveluy C, Pica L, Audet N, Courtemanche R, Lapointe F. Enquête sociale et de santé 1998, 2nd ed. Montreal (QC): Institut de la statistique du Québec: 2000.

21. Tu K, Campbell NRC, Chen ZL, Cauch-Dudek KJ, McAlister FA. Accuracy of administrative databases in identifying patients with hypertension. Open Medicine. 2007;1(1):E18-E26.

22. Rapport du Système national de surveillance des maladies chroniques: L'hypertension au Canada. Ottawa (ON): Public Health Agency of Canada; 2010. 1-28. [Cat.: HP32-4/2010].

23. Pampalon R, Raymond G. Indice de défavorisation matérielle et sociale: son application au secteur de la santé et du bien-être. Santé, société et solidarité. 2003;1:191-208.

24. Pineault R, Provost S, Hamel M, Couture A, Levesque JF. The influence of primary health care organizational models on patients' experience of care in different chronic disease situations. Chronic Dis Inj Can. 2011;31(3):109-20. 
25. Carr-Hill RA, Rice N, Roland M. Socioeconomic determinants of rates of consultation in general practice based on fourth national morbidity survey of general practices. BMJ. 1996; 312(7037):1008-12.

26. Evans RG, Barer ML, Marmor TR, editors. Être ou ne pas être en bonne santé: biologie et déterminants sociaux de la maladie. Montreal (QC): Les presses de l’Université de Montréal; 1996.

27. Mainous AG 3rd, Gill JM. The importance of continuity of care in the likelihood of future hospitalization: is site of care equivalent to a primary clinician? Am J Public Health. 1998;88(10):1539-41.

28. Mercer SW, Watt GC. The inverse care law: clinical primary care encounters in deprived and affluent areas of Scotland. Ann Fam Med. 2007;5(6):503-10.

29. Béland F, Philibert L, Thouez JP, Maheux B. Socio-spatial perspectives on the utilization of emergency hospital services in two urban territories in Quebec. Soc Sci Med. 1990;30(1):53-66.

30. Lemoine O, Simard B, Juneau O, Provost S, Roy Y, Tousignant P. L'utilisation des services de santé par les Montréalais souffrant d'hypertension artérielle, Années 2000-2001 à 2005-2006. Québec (QC): Direction de santé publique de l'Agence de la santé et des services sociaux de Montréal et Institut national de santé publique du Québec; 2010.

31. Roos LL, Walld R, Uhanova J, Bond R. Physician visits, hospitalizations, and socioeconomic status: ambulatory care sensitive conditions in a Canadian setting. Health Serv Res. 2005;40(4):1167-85.

32. Menec VH, Sirski M, Attawar D. Does continuity of care matter in a universally insured population? Health Serv Res. 2005;40(2):389-400.

33. Menec VH, Roos NP, Black C, Bogdanovic B. Characteristics of patients with a regular source of care. Can J Public Health. 2001;92(4):299-303.

34. McCusker J, Roberge D, Lévesque JF, Ciampi A, Vadeboncoeur A, Larouche D. Emergency department visits and primary care among adults with chronic conditions. Med Care. 2010; 48(11):972-80.
35. Birch S, Eyles J, Newbold KB. Equitable access to health care: methodological extensions to the analysis of physician utilization in Canada. Health Econ. 1993;2(2):87-101.

36. Broyles RW, Manga P, Binder DA, Angus DE, Charette A. The use of physician services under a national health insurance scheme. An examination of the Canada Health Survey. Med Care. 1983;21(11):1037-54.

37. Falaschetti E, Chaudhury M, Mindell J, Poulter N. Continued improvement in hypertension management in England: results from the Health Survey for England 2006. Hypertension. 2009;53(3):480-6.

38. Danon-Hersch N, Marques-Vidal P, Bovet P, Chiolero A, Paccaud F, Pécoud A, et al. Prevalence, awareness, treatment and control of high blood pressure in a Swiss city general population: the CoLaus study. Eur J Cardiovasc Prev Rehabil. 2009;16(1):66-72.

39. Kastarinen $M$, Antikainen R, Peltonen $M$, Laatikainen T, Barengo NC, Jula A, et al. Prevalence, awareness and treatment of hypertension in Finland during 1982-2007. J Hypertens. 2009;27(8):1552-9.

40. Marques-Vidal P, Arveiler D, Amouyel P, Bingham A, Ferrieres J. Sex differences in awareness and control of hypertension in France. J Hypertens. 1997;15(11):1205-10.

41. Brindel P, Hanon O, Dartigues JF, Ritchie K, Lacombe JM, Ducimetière $P$, et al. 3C Study Investigators. Prevalence, awareness, treatment, and control of hypertension in the elderly: the Three City study. J Hypertens. 2006;24(1):51-58.

42. Billings J, Anderson GM, Newman LS. Recent findings on preventable hospitalizations. Health Aff (Millwood). 1996;15(3):239-49.

43. Manga P, Broyles RW, Angus DE. The determinants of hospital utilization under a universal public insurance program in Canada. Med Care. 1987;25(7):658-70.

44. Trahan L, Bégin P, Piché J. Recours à l'hospitalisation, à la chirurgie d'un jour et aux services posthospitaliers. In: Enquête sociale et de santé 1988, 2nd ed. Québec (QC): Institut de la statistique du Québec; 2000.
45. Roos N, Burchill C, Carriere K. Who are the high hospital users? A Canadian case study. J Health Serv Res Policy. 2003;8(1):5-10.

46. Levasseur M, Goulet L. Problèmes de santé. In: Enquête sociale et de santé 1988, 2nd ed. Québec (QC): Institut de la statistique du Québec; 2000. 